\title{
Upper Arm Composition as an Indicator of Body Composition and Nutritional Status of Adolescent Boys Aged I0-18 Years
}

\author{
Sen $\mathrm{J}^{1}$, Mondal $\mathrm{N}^{2}$, Ghosh $\mathrm{P}^{3}$
}

\begin{abstract}
Introduction: The upper arm composition is usually assessed based on total upper arm area (TUA), upper arm muscle area (UMA), upper arm fat area (UFA) and arm fat index (AFI). It is closely associated with assessment of body composition and nutritional status. The present study aims to determine the age specific variations in upper arm composition and its usefulness in the assessment of body composition and nutritional status among adolescent boys. Materials and Methods: The study was conducted among 964 boys (aged $10-18$ years) and belonging to the indigenous Rajbanshi population of West Bengal, India. The boys were selected from five different sub-urban government secondary schools located under Siliguri subdivision of Darjeeling district, West Bengal, India. The anthropometric measurements of height, weight, MUAC and TSF were recorded and upper arm composition was estimated based on TUA, UMA, UFA and AFI using standard procedures. The overall body composition was evaluated using body mass index (BMI). Results: There appears to be existence of significant age-specific variations in BMI, UMA and UFA as the boys approached higher ages. The age specific means of TUA, UMA and UFA increased with age. The adolescent boys were observed to be well below the $50^{\text {th }}$ percentiles of the reference population in BMI, TUA, UMA, UFA and AFI. Ageand sex-specific smooth percentile curves were derived for height, weight, TSF, BMI, UMA and UFA using the L, M and S modelling approach for further evaluation of body composition. Conclusion: The present study recommends the assessment of body composition and nutritional status to improve screening of nutritional status using upper arm composition, especially in community settings so as to accurately identify the risk of lower or greater adiposity and muscularity, and thereby proposing a major opportunity to improve health through proper intervention programmes.
\end{abstract}

Key words: Total upper arm area, Upper arm muscle area, Upper arm fat area, Arm fat index, body mass index, adolescent, body composition, Anthropometry, Rajbanshi, India

\section{Introduction}

ody composition is strongly associated with nutritional Dstatus, specific diet, physical exercise, disease and genetics.
'Jaydip Sen, M.Sc, Ph.D. Professor, Department of Anthropology, University of North Bengal, Raja Rammohunpur, Siliguri, Darjeeling 734013, West Bengal, India, ${ }^{2}$ Nitish Mondal, M.Sc, Ph.D. Assistant Professor, Department of Anthropology, Assam University: Diphu Campus, Diphu, Karbi Anglong 782462, Assam, India, ${ }^{3}$ Partha Ghosh, M.Sc. Ex- Post Graduate Student, Department of Anthropology, University of North Bengal, Raja Rammohunpur, Siliguri, Darjeeling 734013, West Bengal, India.

\author{
Address for correspondence: \\ Dr. Nitish Mondal, M.Sc., Ph.D. \\ Assistant Professor, Department of Anthropology \\ Assam University: Diphu Campus, \\ Diphu, Karbi Anglong 782462, Assam, India \\ E-mail: nitishanth@gmail.com \\ Tel +91-9613712613
}

\section{How to cite}

Sen J, Mondal N, Ghosh P. Upper Arm Composition as an Indicator of Body Composition and Nutritional Status of Adolescent Boys Aged 10-18 Years. J Nepal Paediatr Soc 2015;35(2):152-161.

doi: http://dx.doi.org/10.3126/jnps.v35i2.13250

This work is licensed under a Creative Commons Attribution 3.0 License.

\section{(c) (7)}

The determination of body composition allows for the quantitative assessment of muscle mass and adiposity changes that reflects nutritional intake, losses and expenses over a time period $(1,2,3,4)$. Thus, changes in body composition are very important in clinical and epidemiological 
investigations. Poor body composition and nutritional status can lead to increased morbidity, poor physical activity and performances. So the evaluation of body composition of nutritionally vulnerable segments of a population becomes a priority for the researcher. It is quite difficult to assess body composition with fair accuracy and several techniques have been developed only in the last decade for an accurate estimation and distribution of body adiposity $(2,3,5,6)$. These methods include underwater weighing, air displacement plethysmography, bioelectrical impedance analysis and dual-energy X-ray absorptiometry. However, anthropometric measurements still constitute an important method of choice of researchers for such assessments in clinical and epidemiological investigations. The indirect assessment of muscularity and adiposity are widely being done using skinfolds thickness, body mass index (BMI) and circumference measurements (4-7). Several researchers have utilized these anthropometric measurements and $\mathrm{BMI}$ to estimate body composition variations in children $(1,3,4,6,8)$.

The upper arm composition has received considerable attention during the last few decades, but has not been widely adopted for routine assessments of body composition among children and adolescents. Recently several studies have reported direct associations of disease, bio-chemical changes, clinical symptoms and nutritional status with upper arm composition among children $(9,10)$. Upper arm composition is usually assessed using total upper arm area (TUA), upper arm muscle area (UMA), upper arm fat area (UFA) and arm fat index (AFI). These are determined from mid-upper-arm circumference (MUAC) and triceps (TSF) skinfold thickness $(5,7)$. However, few studies have utilized upper arm composition to determine nutritional status of children, adolescents and adults (8,11-17). Studies are also scarce in the domain of standard growth references for school-aged children and adolescents related to upper arm composition $(7,12,13,15)$.

The adolescent period is a very important phase in the life span of an individual. It is defined as the period of transition between childhood and adulthood and is characterized by an exceptionally rapid rate of growth $(1,6)$. During the period of adolescence, the nutrient requirements of the body are high and as such the nutritional status of these individuals needs to be monitored closely as they constitute the next generation of parents. Undernutrition among adolescents constitutes a major focus of nutritional research in India. There also appears a need to develop a database on the nutritional status of adolescents from different parts of the country. This will enable the government and non-governmental agencies to formulate policies and initiate strategies for well-being of the adolescents. But such a database for the country is lacking at the moment. There is little available information on the nutritional status of adolescents from India, although some important scientific papers are mentionable (18-22). A few comparative studies have reported that adolescents were observed to have poor growth attainment, late sexual maturity and body composition than their reference counterparts, especially among boys (21-23). The current literature shows a paucity of literature in the field of body composition, nutritional assessment vis-à-vis upper arm composition among children and adolescents belonging to various Indian populations $(8,14,15,16)$. Given the above, the objectives of this present study were to determine the age specific variations in upper arm composition and its usefulness in the assessment of body composition among adolescent boys aged 10-18 years.

\section{Material and Methods}

Nature of the population and subjects: Popularly known as North Bengal, the northern part of the state of West Bengal, India, comprises of seven districts and is the home to a number of tribal and indigenous populations (such as Lepcha, Rabha, Meche, Toto, Oraon, Santal and Munda) and non-tribal populations (such as Rajbanshi, Bengali Caste and Bengali Muslim). Given the region's general backwardness in health care, educational and medical facilities, these populations remain very vulnerable to undernutrition $(8,19,20)$. Although there are some studies on the assessment of body composition and nutritional status among individuals belonging to these populations, there is a lack of such studies among adolescents of the same. As far as the latter is concerned, a detailed literature search has yielded just two studies in this regard and here those of Mondal and Sen (4) Sen et al. (8) may be cited.

The most widely distributed indigenous population in North Bengal is the Rajbanshi. According to the National Census 2001, they constitute the largest and the number of the Scheduled Caste population of West Bengal (18.40\% and nearly 3.4 million, respectively). It is generally agreed that the Rajbanshi shows resemblances with the Koch population of the neighboring state of Assam and it is been conjectured that they belong to a mixed ethnicity of Austroasian/ Dravidian and Mongolian (19). Researchers have 
opined that they belong to a Dravidian stock that came in contact with the heterogeneous Mongoloid populations. A study on genetic markers among the populations of north-eastern India has reported that the Rajbanshi was a semi-Hinduized caste group located in-between the clusters comprising the Caucasoid caste and Mongoloid tribal populations (24).

The data for the present study were collected from adolescent Rajbanshi boys (aged 10 - 18 years). The boys were the students of five different sub-urban government secondary schools located under the subdivision of Siliguri, district Darjeeling of the region. The schools were identified and selected based on identical subject strength, easy accessibility by road and homogeneity using a purposive sampling method. The predominance of Rajbanshi boys was the sole criterion behind the selection of the schools. The boys were selected using a multi-stage stratified sampling method. The physical features and surnames were utilized to identify the subjects and subsequently their ethnicity was verified from the official records. A total of 1127 Rajbanshi boys were initially identified and approached to voluntarily participate in the study. Of them, 111 boys refused to take part in the study. Out of the remaining 1016 boys who agreed to participate, 52 were excluded as their dates of birth could not be verified from the governmental records. Hence, the final sample consisted of 964 boys (subjects) aged from 10 years to 18 years. Special care was taken so that each age had a minimum of 100 boys. All the subjects were free from any physical deformity and not suffering from any form of disease at the time of examination. Necessary consents and permissions were obtained from the local and school authorities prior to commencement of the study. A verbal consent was also taken from each subject and their parents before initiating the phase of data collection. The study was conducted in accordance with the ethical guidelines of human experiments as laid down in the Helsinki Declaration of 2000 (25).

Socio-economic data recorded: Parents of the boys were interviewed on the basis of a structured schedule so as to ascertain their socio-economic status. Relevant data on socio-economic and demographic variables (ethnic group, family size, parents' education, occupation, family income and dependent children in family) were recorded for this purpose. A modified scale of Kuppuswamy was used to ascertain the socio-economic status (SES) (26). It was subsequently observed that the boys belonged to a lower to a middle SES as ascertained by the using modified socioeconomic scale mentioned above. After determining the SES, socio-economic and demographic variables were not taken into consideration in further statistical analysis.

Anthropometric measurements obtained: The anthropometric measurements of height, weight, midupper arm circumference (MUAC) and triceps skin fold (TSF) were recorded following standard anthropometric procedures (27). The subjects wore minimum clothing and were without any footwear at the time of recording the measurements. Height of the subjects was recorded with the help of an anthropometer rod, with the head held in the Frankfurt Horizontal plane. Height was measured to the nearest $0.10 \mathrm{~cm}$. Weight of the subjects was recorded using a portable weighing scale to the nearest $100 \mathrm{~g}$. The MUAC was taken at the point midway between the acromion and the radiale of the upper arm using a plastic coated non-stretchable measuring tape on the left side of each subject to the nearest $0.10 \mathrm{~cm}$. The skin fold measurement of TSF was made using a Holtein skinfold caliper calibrated to exert a constant pressure of $10 \mathrm{~g} / \mathrm{mm}^{2}$ on the left side of each subject to the nearest $0.20 \mathrm{~mm}$.

The intra-observer and inter-observer technical error measurements (TEM) were calculated to improve the precision of anthropometric measurements by utilizing the standard procedure of Ulijaszek and Kerr (28). The TEM was calculated using the following equation:

$\operatorname{TEM}=\mathrm{V}\left(\sum \mathrm{D}^{2} / 2 N\right), \quad \mathrm{D}=$ difference between the measurements, $\mathrm{N}=$ number of individuals.

The co-efficient of reliability (R) was calculated from TEM using the following equation:

$\mathrm{R}=\left\{1-(T E M)^{2} / S D^{2}\right\}, S D=$ standard deviation of the measurements.

Height, weight, MUAC and TSF were recorded from 50 adolescent boys other than those selected for the study by two of the authors (PG and NM) for the calculation of TEM. Very high values of $R(>0.975)$ were obtained for all the four measurements and these values were observed to be within the acceptable limits of $R=0.95$ (28). Hence, the measurements recorded by PG and NM were considered to be reliable and reproducible. All the measurements in course of the present study were subsequently recorded by both the authors (PG and NM).

Assessment of body composition: The upper arm composition was estimated from MUAC and TSF by the standard equations (7). These equations are appended below: 
1. Total upper arm area $\left\{\right.$ TUA $\left(\mathrm{cm}^{2}\right)=\operatorname{MUAC}(\mathrm{cm})^{2} /$ $4 \pi\}$

2. Upper arm muscle area [UMA $\left(\mathrm{cm}^{2}\right)=[\operatorname{MUAC}(\mathrm{cm})$ $\left.-\{\operatorname{TSF}(\mathrm{cm}) \times \pi)\}^{2} / 4 \pi\right]$

3. Upper arm fat area $\left\{\right.$ UFA $\left(\mathrm{cm}^{2}\right)=$ TUA $\left(\mathrm{cm}^{2}\right)-U M A$ $\left.\left(\mathrm{cm}^{2}\right)\right\}$

4. Arm fat index $\{A F I=(U F A / T U A) \times 100\}$.

The overall body composition was evaluated using BMI. The BMI was calculated by the following standard equation:

BMI $\left(\mathrm{kg} / \mathrm{m}^{2}\right)=$ weight $(\mathrm{kg}) /$ height $\left(\mathrm{m}^{2}\right)$.

Statistical analysis: The statistical analysis was done using Statistical Package for Social Sciences (version 17.0). The one-sample Kolmogorov-Smirnov test was used to compare the observed cumulative distribution functions for each of the anthropometric variables with respect to a specified theoretical distribution $(p>0.05)$. One way analysis of variance (ANOVA) was utilized to identify the mean differences among the anthropometric variables with respect to the different ages. A post-hoc test using Scheffe procedure was done to compare the multiple comparisons of mean between the anthropometric variables when applicable within the ages. The least median square (LMS) model analysis was used by taking into the account the degree of skewness (L), central tendency (M: Median) and dispersion or the generalized coefficient of variation (S) for the calculation of reference percentiles curves. This model is a concept of an age varying adjustment for skewness based on the Box-Cox transformation. The method converts the measurements for a subject of known age and sex to evaluate percentile and standard deviation score or z-score $(29,30)$. The LMS method software computer program fits smooth percentile curves to the reference data using the LMS method as described by Cole and Green (29). The age-specific height, weight, BMI, TSF, UMA and UFA percentile curves with $3^{\text {rd }}, 10^{\text {th }}, 15^{\text {th }}, 25^{\text {th }}$, $50^{\text {th }}, 75^{\text {th }}, 90^{\text {th }}$ and $97^{\text {th }}$ smoothed percentile lines for the boys were plotted separately for further evaluation of nutritional status. The results were considered to be significant at $p<0.05$ level.

\section{Results}

The age-wise distribution of the means ( \pm S.D.) of the anthropometric variables among the Rajbanshi boys is depicted in Table 1 . The age specific mean height and weight increased with age from early adolescence but height decreased in the ages from 17 to 18 years. Boys belonging to the age groups of 10 to 14 years have showed acceleration in growth patterns in height and weight. The age specific mean MUAC was also increased with age but no such age specific trend was observed in TSF. The mean TSF values ranged from $5.57 \mathrm{~mm}$ (in 10 years) to $6.97 \mathrm{~mm}$ (in 18 years). Using ANOVA, statistically significant $(p<0.05)$ differences were observed in weight (F-value=138.10; d.f.: 8, 963), height (F-value=165.19; d.f.: 8, 963), TSF (F-value=5.31; d.f.: 8, 963) and MUAC (F-value=47.48; d.f.: 8, 963) variables with respect to age (Table 1 ).

Assessment of upper arm and body composition: The age specific means ( \pm S.D.) of the derived anthropometric body composition characteristics among the adolescent boys are presented in Table 1. There appears to be an existence of significant age specific variation in height, weight, BMI, UMA and UFA as the boys approached to higher ages. The BMI gradually increased with age from 10 years to 14 years, followed by a slight decrease in 16 years $(17.48 \mathrm{~kg} /$ $\mathrm{m}^{2}$ ) and then continued to rise reaching its highest peak in the age of 18 years $\left(20.21 \mathrm{~kg} / \mathrm{m}^{2}\right)$. The age specific means of TUA and UFA increased with age, with exceptions in 15 years $\left(36.10 \mathrm{~cm}^{2}\right)$ and 14 years $\left(6.11 \mathrm{~cm}^{2}\right)$. The age specific mean values of UMA increased with age in the later ages (14 years to 18 years) but AFI did not show any trend with respect to age. The age specific mean AFI was observed to be lower in 17 years (16.91) and higher in 13 years (19.86) The age specific mean differences were observed to be statistically significant $(\mathrm{p}<0.05)$ in $\mathrm{BMI}(\mathrm{F}-$ Value= 21.49; d.f.: 8, 963), TUA (F-Value= 49.18; d.f.: 8, 963), UMA (F-Value=41.73; d.f.: 8, 963), UFA (F-Value=19.65; d.f.: 8, 963), and AFI (F-Value=6.22; d.f.: 8, 963), using ANOVA (Table 1). Age specific smooth percentile curves were also derived using LMS procedures for height, weight, BMI, TSF, UMA and UFA among Rajbanshi boys and are depicted in Figure 1.

Comparison with the Reference Population: The comparison of age specific mean height and BMI values obtained in the present study with the National Health and Nutritional Examination Survey (NHANES-III) (31), Centres for Disease Control and Prevention (CDC) (32) and World Health Organization (WHO) (33) reference population has been depicted in Figure 2. The lower attainment of height and BMI respect to age is generally considered as long term linear growth retardation (i.e., stunting) and chronic energy deficiency (i.e., thinness), respectively (33). The age specific mean height were below the $25^{\text {th }}$ percentile of the all considered growth reference populations and the boys who reached the higher ages of 13 to 18 years and 15 to 18 years 
were found to be below the $5^{\text {th }}$ percentile for NHAHES (31), and both $\mathrm{CDC}$ (32) and WHO (33) indicates chronic linear growth retardation, respectively. The age specific mean values of BMI were observed to be below the $50^{\text {th }}$ percentile of NHANES (31), whereas the age specific mean $\mathrm{BMI}$ values were below the $25^{\text {th }}$ percentile in ages 10 years, 11 years, 13 years, 14 years to 16 years of $\mathrm{CDC}$ (32). The comparison with WHO (33) reference population showed that age specific mean $\mathrm{BMI}$ values were well above the $50^{\text {th }}$ percentiles with exception observed in 10 years, 11 years, 16 years and 17 years but the values were observed to be below the $25^{\text {th }}$ percentile (Figure 2 ).

The comparison of age specific mean upper arm composition variables of TUA, UMA, UFA and AFI values obtained in the present study with the NHANESIII (31) reference population for further evaluation of body composition and nutritional status has been depicted in Figure 3. The age specific mean values of TUA and UFA were found to below the $25^{\text {th }}$ percentile of NHANES reference, but the only exception was observed for 17 years (i.e., TUA, $<5^{\text {th }}$ percentile) and 15 years (i.e., UFA, $<50^{\text {th }}$ percentile). The age specific mean values of UMA were observed to be below the $5^{\text {th }}$ percentiles values in 12 years and 15 to 18 years boys. The age specific mean values of UMA were also observed to be below the $25^{\text {th }}$ percentiles in 11 years, 13 years and 14 years ages while the value was below the $50^{\text {th }}$ percentiles in 10 years. The age specific mean values of $\mathrm{AFI}$ were observed to be below the $25^{\text {th }}$ percentiles for the age specific mean values of 10 to 13 years boys. Age specific mean values of AFI varied with the age and it was observed well within the $50^{\text {th }}$ to $75^{\text {th }}$ percentiles in the age groups of 14 to 18 years ages of NHANES-III reference population data (Figure 3).

Table 1: Age-specific subject distribution, descriptive statistics (mean \pm SD) of the anthropometric and body composition variables and within age differences among the Rajbanshi boys

\begin{tabular}{|c|c|c|c|c|c|c|c|c|c|c|}
\hline $\begin{array}{l}\text { Variables } \\
(\mathrm{N}=964)\end{array}$ & $\begin{array}{l}10 \text { year } \\
(\mathrm{N}=105)\end{array}$ & $\begin{array}{l}11 \text { year } \\
(\mathrm{N}=104)\end{array}$ & $\begin{array}{c}12 \text { year } \\
(\mathrm{N}=107)\end{array}$ & $\begin{array}{l}13 \text { year } \\
(\mathrm{N}=108)\end{array}$ & $\begin{array}{c}14 \text { year } \\
(\mathrm{N}=105)\end{array}$ & $\begin{array}{c}15 \text { year } \\
(N=104)\end{array}$ & $\begin{array}{c}16 \text { year } \\
(\mathrm{N}=106)\end{array}$ & $\begin{array}{c}17 \text { year } \\
(\mathrm{N}=110)\end{array}$ & $\begin{array}{l}18 \text { year } \\
(\mathrm{N}=115)\end{array}$ & F-value \\
\hline Weight (kg) & $\begin{array}{l}26.13 \\
\pm 4.31\end{array}$ & $\begin{array}{l}29.17 \\
\pm 6.33\end{array}$ & $\begin{array}{r}31.83 \\
\pm 6.76\end{array}$ & $\begin{array}{r}36.41 \\
\pm 8.23\end{array}$ & $\begin{array}{r}39.30 \\
\pm 8.39\end{array}$ & $\begin{array}{r}43.59 \\
\pm 7.59\end{array}$ & $\begin{array}{r}44.27 \\
\pm 8.35\end{array}$ & $\begin{array}{l}47.50 \\
\pm 7.25\end{array}$ & $\begin{array}{r}50.35 \\
\pm 7.81\end{array}$ & $138.10^{*}$ \\
\hline Height $(\mathrm{cm})$ & $\begin{array}{c}131.10 \\
\pm 8.35\end{array}$ & $\begin{array}{c}136.58 \\
\pm 9.95\end{array}$ & $\begin{array}{l}140.07 \\
\pm 10.14\end{array}$ & $\begin{array}{c}147.26 \\
\pm 9.75 \\
\end{array}$ & $\begin{array}{c}151.42 \\
\pm 9.17\end{array}$ & $\begin{array}{c}154.15 \\
\pm 8.41\end{array}$ & $\begin{array}{c}159.22 \\
\pm 7.40\end{array}$ & $\begin{array}{c}158.99 \\
\pm 5.38\end{array}$ & $\begin{array}{c}157.98 \\
\pm 5.57\end{array}$ & $165.19 *$ \\
\hline MUAC (cm) & $\begin{array}{l}18.52 \\
\pm 2.03\end{array}$ & $\begin{array}{l}19.07 \\
\pm 2.25\end{array}$ & $\begin{array}{l}19.16 \\
\pm 1.93\end{array}$ & $\begin{array}{l}20.31 \\
\pm 2.54\end{array}$ & $\begin{array}{l}21.34 \\
\pm 2.37\end{array}$ & $\begin{array}{l}21.14 \\
\pm 2.49\end{array}$ & $\begin{array}{l}21.57 \\
\pm 2.11\end{array}$ & $\begin{array}{l}22.13 \\
\pm 1.94\end{array}$ & $\begin{array}{l}23.03 \\
\pm 2.93\end{array}$ & $47.48^{*}$ \\
\hline $\mathrm{TSF}(\mathrm{mm})$ & $\begin{array}{c}5.57 \\
\pm 1.62 \\
\end{array}$ & $\begin{array}{c}6.06 \\
\pm 1.99 \\
\end{array}$ & $\begin{array}{c}6.47 \\
\pm 1.77 \\
\end{array}$ & $\begin{array}{c}5.90 \\
\pm 1.64 \\
\end{array}$ & $\begin{array}{c}5.76 \\
\pm 1.66 \\
\end{array}$ & $\begin{array}{c}6.37 \\
\pm 2.25 \\
\end{array}$ & $\begin{array}{c}5.81 \\
\pm 1.92 \\
\end{array}$ & $\begin{array}{c}6.17 \\
\pm 2.28 \\
\end{array}$ & $\begin{array}{c}6.97 \\
\pm 2.27 \\
\end{array}$ & $5.31^{*}$ \\
\hline BMI $\left(\mathrm{kg} / \mathrm{m}^{2}\right)$ & $\begin{array}{l}15.34 \\
\pm 3.04 \\
\end{array}$ & $\begin{array}{l}15.72 \\
\pm 3.43 \\
\end{array}$ & $\begin{array}{l}16.45 \\
\pm 4.12 \\
\end{array}$ & $\begin{array}{l}16.81 \\
\pm 3.53 \\
\end{array}$ & $\begin{array}{l}17.23 \\
\pm 4.17\end{array}$ & $\begin{array}{l}18.44 \\
\pm 3.52 \\
\end{array}$ & $\begin{array}{l}17.48 \\
\pm 3.32 \\
\end{array}$ & $\begin{array}{l}18.87 \\
\pm 3.25 \\
\end{array}$ & $\begin{array}{l}20.21 \\
\pm 3.19 \\
\end{array}$ & $21.49 *$ \\
\hline TUA $\mathrm{cm}^{2}$ & $\begin{array}{l}27.63 \\
\pm 6.17\end{array}$ & $\begin{array}{l}29.05 \\
\pm 6.80\end{array}$ & $\begin{array}{l}29.18 \\
\pm 5.63\end{array}$ & $\begin{array}{l}33.12 \\
\pm 8.03\end{array}$ & $\begin{array}{l}36.73 \\
\pm 7.82\end{array}$ & $\begin{array}{l}36.10 \\
\pm 8.27\end{array}$ & $\begin{array}{l}37.40 \\
\pm 7.26\end{array}$ & $\begin{array}{l}39.26 \\
\pm 6.80\end{array}$ & $\begin{array}{c}43.01 \\
\pm 11.35\end{array}$ & $49.18^{*}$ \\
\hline UMA $\mathrm{cm}^{2}$ & $\begin{array}{l}22.60 \\
\pm 5.97\end{array}$ & $\begin{array}{l}23.63 \\
\pm 6.27\end{array}$ & $\begin{array}{l}22.83 \\
\pm 4.76\end{array}$ & $\begin{array}{l}26.76 \\
\pm 7.61\end{array}$ & $\begin{array}{l}30.69 \\
\pm 7.03\end{array}$ & $\begin{array}{l}29.06 \\
\pm 7.36\end{array}$ & $\begin{array}{l}30.82 \\
\pm 6.84\end{array}$ & $\begin{array}{l}32.40 \\
\pm 7.20\end{array}$ & $\begin{array}{c}34.81 \\
\pm 10.07\end{array}$ & $41.73 *$ \\
\hline UFA $\mathrm{cm}^{2}$ & $\begin{array}{c}5.03 \\
\pm 1.44 \\
\end{array}$ & $\begin{array}{c}5.52 \\
\pm 1.67 \\
\end{array}$ & $\begin{array}{c}6.27 \\
\pm 1.76\end{array}$ & $\begin{array}{c}6.35 \\
\pm 1.70\end{array}$ & $\begin{array}{c}6.11 \\
\pm 1.90\end{array}$ & $\begin{array}{c}6.85 \\
\pm 2.67\end{array}$ & $\begin{array}{c}6.55 \\
\pm 2.08\end{array}$ & $\begin{array}{c}7.28 \\
\pm 2.51\end{array}$ & $\begin{array}{c}7.96 \\
\pm 2.51\end{array}$ & $19.65 *$ \\
\hline AFI & $\begin{array}{l}18.67 \\
\pm 5.22\end{array}$ & $\begin{array}{l}19.37 \\
\pm 5.10\end{array}$ & $\begin{array}{l}19.81 \\
\pm 4.84\end{array}$ & $\begin{array}{r}19.86 \\
\pm 5.48\end{array}$ & $\begin{array}{l}16.91 \\
\pm 4.63\end{array}$ & $\begin{array}{l}19.06 \\
\pm 6.44\end{array}$ & $\begin{array}{r}17.89 \\
\pm 5.47\end{array}$ & $\begin{array}{l}18.50 \\
\pm 5.56\end{array}$ & $\begin{array}{l}18.93 \\
\pm 5.50\end{array}$ & $6.22 *$ \\
\hline
\end{tabular}

$*_{p}<0.05$ 

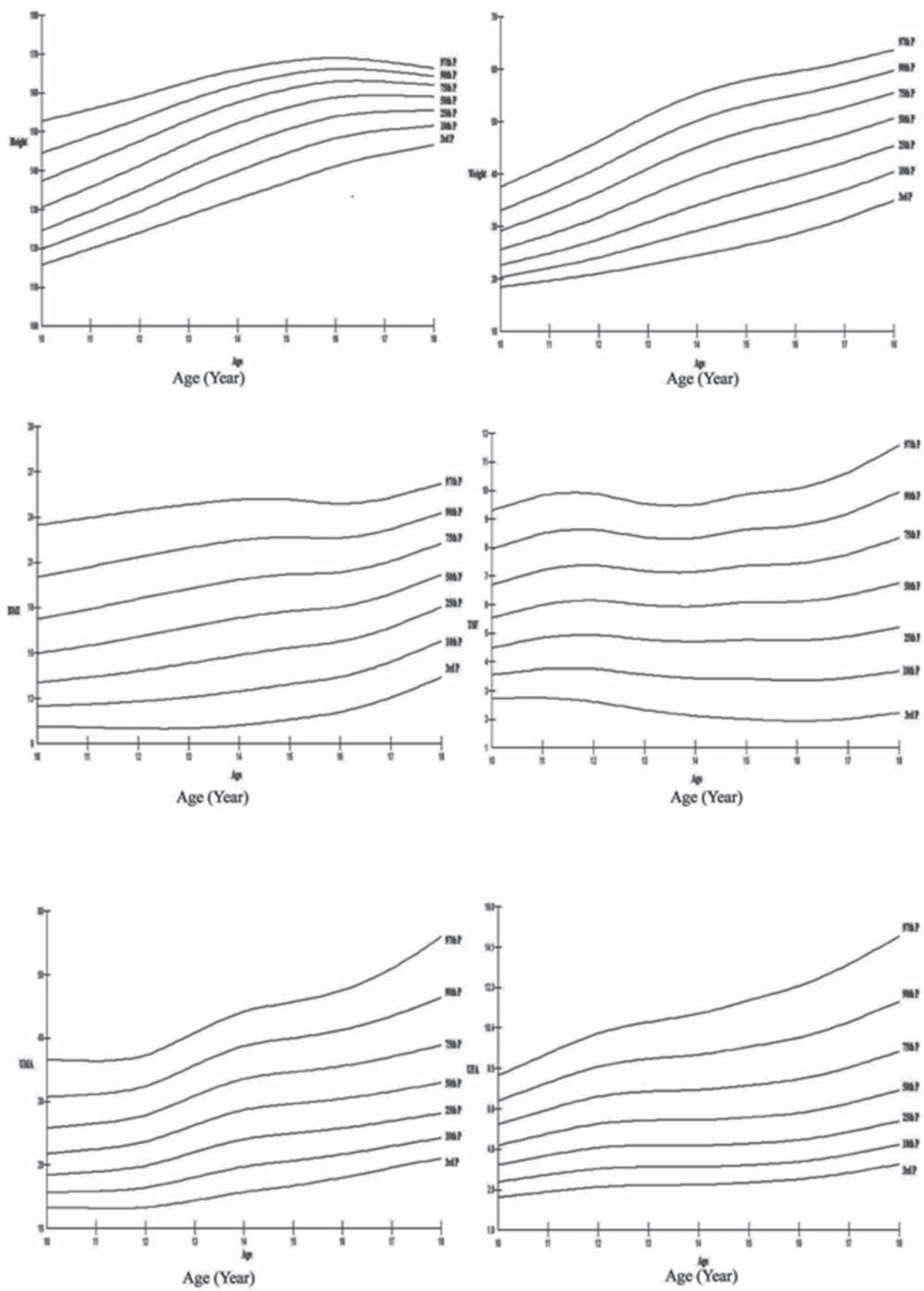

Fig 1: Percentile curves of age specific mean height, weight, BMI, TSF, UMA and UFA among the Rajbanshi boys 


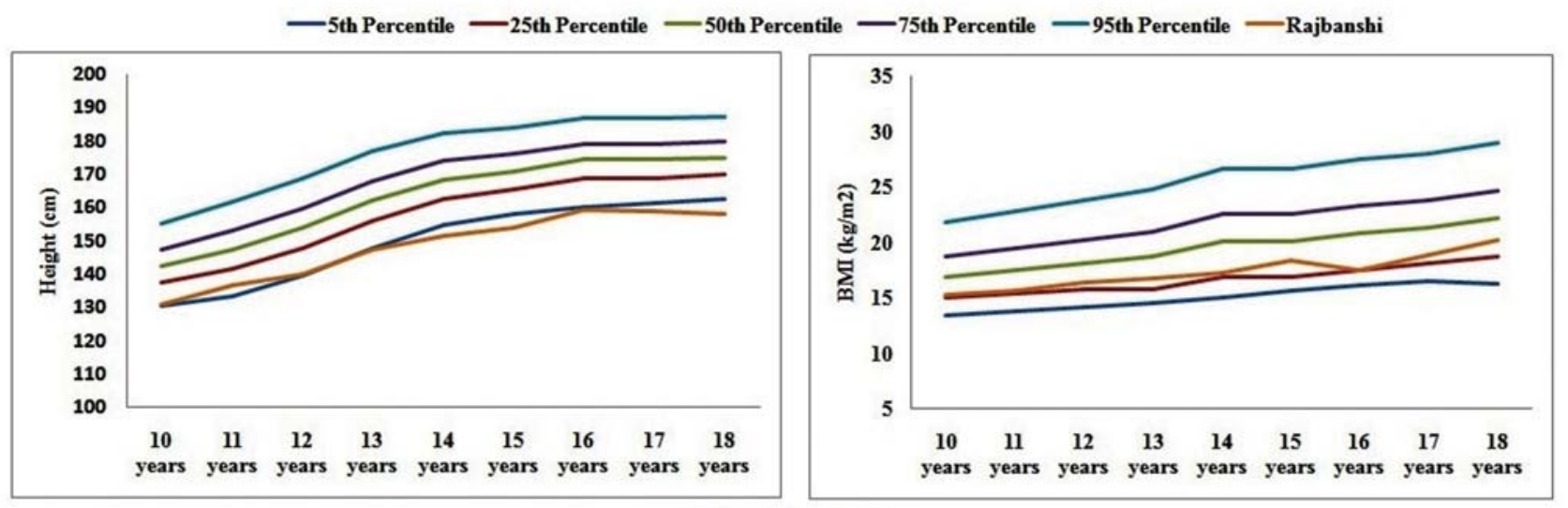

\section{NHANES-III (1996)}
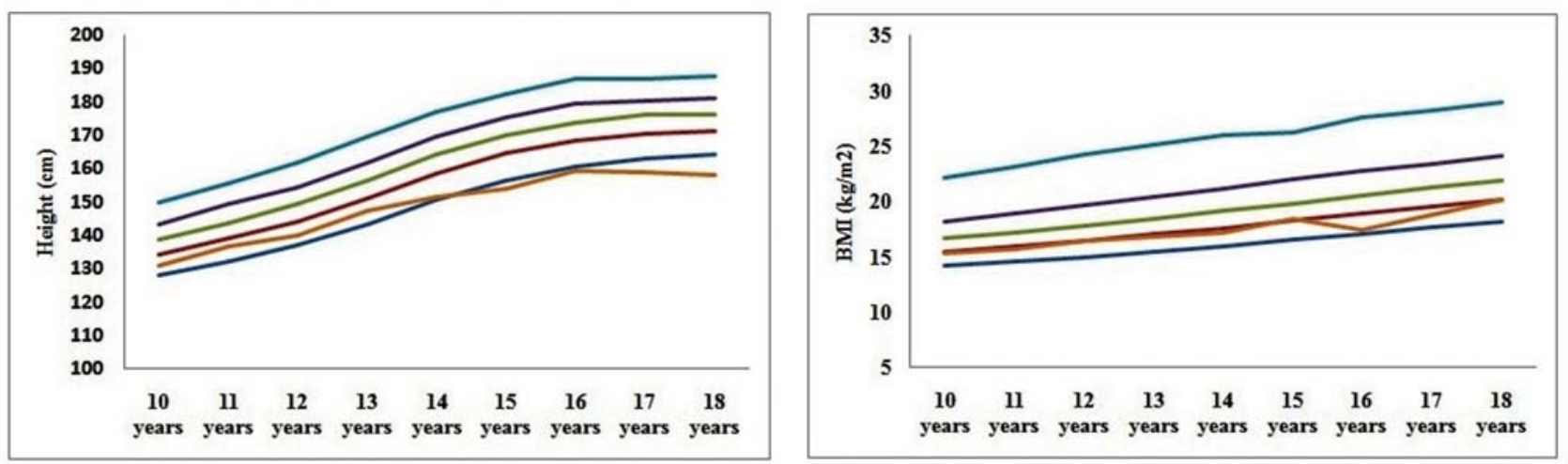

CDC (2000)
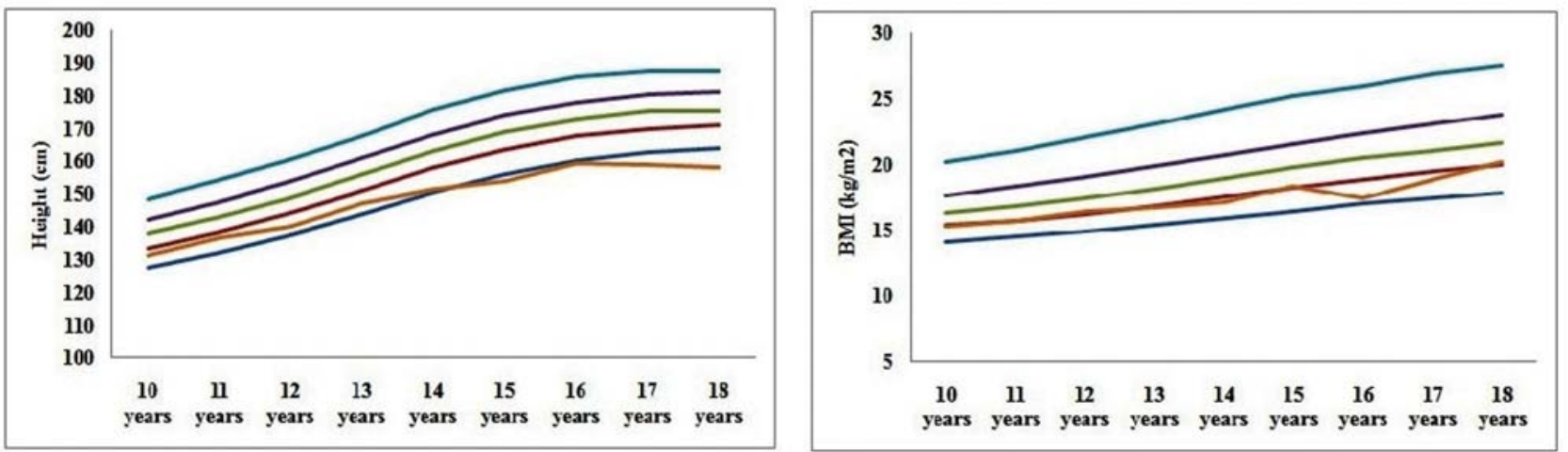

\section{WHO (2007)}

Fig 2: Age specific mean anthropometric variables of height and BMI of the Rajbanshi boys as compared with $5^{\text {th }}, 25^{\text {th }}$, $50^{\text {th }}, 75^{\text {th }}$ and $95^{\text {th }}$ percentiles of NHANES-III (31), CDC (32) and WHO (33) Reference populations.

\section{Discussion}

Body composition assessment using anthropometric measurements is still an important technique of preference and proving increasingly important in epidemiological and clinical investigations $(4,5,8,16,17)$. Several studies have used the skinfolds measurements to quantify the amount of muscularity and adiposity in children and adolescents $(4,8,11,14$ 17). They have also advocated that these measures are very useful to monitor body-composition, nutritional status and for evaluating the effects of target specific intervention and supplementary programmes.
Changes in body composition characteristics have been evaluated among Rajbanshi adolescent boys in the present study, especially when they approached the stage of puberty. Several studies have reported similar changes in upper arm composition related to sexual characteristics attainment during puberty $(8,14,15)$. The results of the present study suggest that adolescent boys were observed to be well below the $50^{\text {th }}$ percentiles of the reference populations (31-33) in height, BMI (Figure 2) and TUA, UMA, UFA and AFI of the NHANES-III reference (31) (Figure 3). Similar studies have already reported body composition attainment as compared to their reference counterparts among 

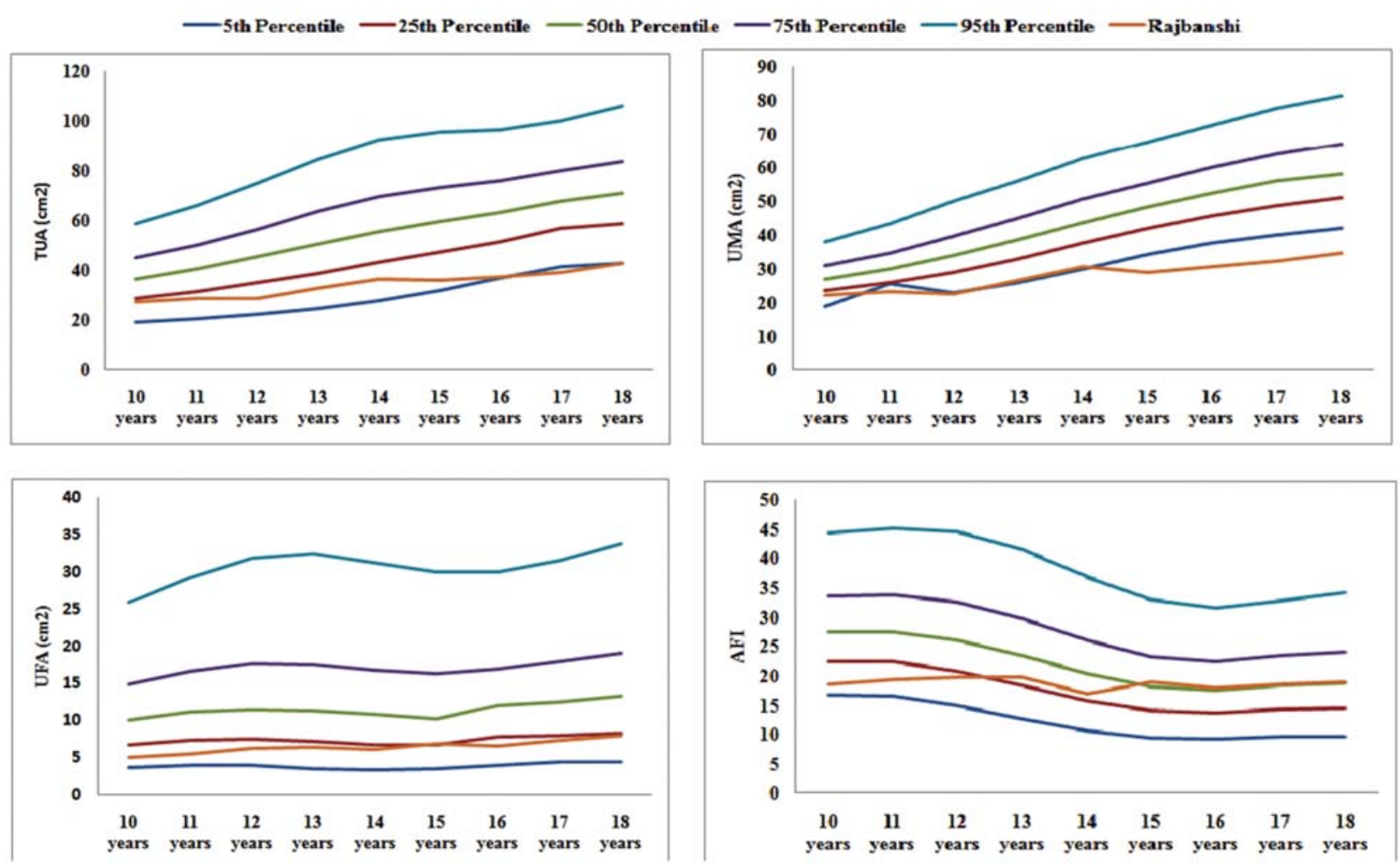

Fig 3: Age specific mean upper arm composition variables of TUA, UMA, UFA and AFI of the Rajbanshi boys as compared with $5^{\text {th }}, 25^{\text {th }}, 50^{\text {th }}, 75^{\text {th }}$ and $95^{\text {th }}$ percentiles of NHANES-III (33) Reference populations.

Indian children and adolescents from Bengalee Muslim (8), Santal (14), Khasi (15) and Sonowal Kachari (16) populations. Therefore, the results of the present study are consistent with those previously reported studies suggesting a poor caloric and protein reserve among the adolescents. Therefore, the assessment of body composition allows a quantitative assessment of muscle-mass and adiposity changes that reflects nutritional intake, losses and expenses over time period in children and adolescents $(2,3,6)$. This achievement of unsatisfactory nutritional status may be attributed due to their poor living conditions and lower SES. The socio-economic scale of Kuppuswamy's (26) used in the present study has shown that the boys belonged to a lower to middle SES group. It has been reported that poor living conditions and environmental variations can influence physical growth attainment patterns among adolescents $(8,18)$ and these could be determinant factors in the present study. Furthermore, these differences can be initially attributed to the different related factors such as age-sex, genotype, diet and eating habits, physical exercise, SES and environmental conditions during childhood and adolescence (1,4$6,14)$.

The poor upper arm composition among the Rajbanshi adolescent boys is probably attributed to lower-SES and higher early age undernutrition that are prevalent in the vulnerable segments in Indian populations $(4,8,16,34)$. Furthermore, early life experiences involving adverse environmental condition, intrauterine growth retardation, poor physical growth in early childhood and subsequent catch-up growth can also have an impact on growth attainment, poor body composition, and health related outcomes later in adulthood $(35,36)$. Moreover, this unsatisfactory body composition largely reflects the inadequate nutrition during early-childhood and is likely to be a consequence of well-known phenomenon of prolonged breastfeeding combined with inadequate weaning food of low energy-density among Indian children (34).

Possibly the poor physical growth attainment among the nutritionally vulnerable segments in developing countries such as India is probably because of the more pronounced influence of specific non-genetic factors such as infectious disease and undernutrition (35-36). Moreover, researchers have already observed a significant association between poor nutritional status and upper arm composition with disease related morbidity and mortality among children and adolescents (37-38). Therefore, body composition assessment and evaluation and 
monitoring of nutritional status should be integrated into routine epidemiological and clinical practices for initial assessment and sequential follow-up of health and nutritional status assessment studies. However, it needs to kept in mind that upper arm composition can provide a better assessment of muscularity and adiposity over conventional anthropometric measures, but it is still relatively insensitive to short-term alterations in body-composition $(8,14,16)$. The main limitation of the present study that has determined the age specific trends of upper arm composition using a set of simple anthropometric measurements of a homogenous sample and a cross-sectional study design is that it would be difficult to draw a major conclusion. A longitudinal design and heterogeneous population in clinical and/or epidemiological settings could be more useful to explain the possible association of upper arm composition with undernutrition and disease related mortality and morbidity.

\section{Conclusion}

Upper arm composition is very useful to monitor nutritional status and evaluating the effects of target specific intervention and supplementary programmes. Moreover, currently recommended anthropometric measures (i.e., stunting and thinness) are unable evaluate the body composition. Therefore, the measures of upper arm composition should be used with conventional anthropometric measures for a comprehensive estimation of nutritional status and body composition. Future investigations are necessary to understand the relationship between upper arm adiposity measures with body fat percent, central and regional body adiposity measures. The present study recommends assessment of body composition and nutritional status to improve screening of undernutrition using upper arm composition, especially in epidemiological and clinical investigations so as to accurately identify the relative risk of lower or greater adiposity and muscularity, and thereby propose a major opportunity to improve health through proper intervention programmes and to reduce the subsequent manifestations in population.

Acknowledgements: The help and co-operation of the subjects, schools and local authorities are gratefully acknowledged. The help of the Department of Anthropology, University of North Bengal is also acknowledged.

Funding: University Grants Commission

Conflict of Interest: Nil

Permission from IRB: Yes

\section{References}

1. Wells JC. Sexual dimorphism of body composition. Best Pract Res Clin Endocrinol Metab 2007;21:41530.

2. Thibault R, Pichard C. The evaluation of body composition: a useful tool for clinical practice. Ann Nutr Metab 2012;60:6-16.

3. Thibault R, Genton L, Pichard C. Body composition: why, when and for who? Clin Nutr 2012;31:435-47.

4. Sen J, Mondal N. Fat mass and fat-free mass as indicators of body composition among Bengalee Muslim children. Ann Hum Biol 2013;40:286-93.

5. Rolland-Cachera MF. Body composition during adolescence: methods, limitations and determinants. Horm Res 1993;39:S25-40.

6. Wells JCK. 2010. The evolutionary biology of human body fatness: thrift and control. Cambridge: Cambridge University Press.

7. Frisancho AR. 1989. Anthropometric standard for the assessment of growth and nutrition status. University of Michigan Press: Ann Arbor, MI.

8. Sen J, Mondal N, Dey S. Assessment of the nutritional status of children aged 5-12 years using upper arm composition. Ann Hum Biol 2011;38:752-59.

9. Piratelli CM, Telarolli Junior R. Nutritional evaluation of stage 5 chronic kidney disease patients on dialysis. Sao Paulo Med J 2012;130:392-97.

10. Hoffmeister PA1, Storer BE, Macris PC, Carpenter PA, Baker KS. Relationship of body mass index and arm anthropometry to outcomes after pediatric allogeneic hematopoietic cell transplantation for hematologic malignancies. Biol Blood Marrow Transplant 2013;19:1081-86.

11. Bolzan A, Guimarey L, Frisancho AR. Study of growth in rural school children from Buenos Aires, Argentina using upper arm muscle area by height and other anthropometric dimensions of body composition. Ann Hum Biol 1999;26:185-93.

12. Gültekin T, Özer BK, Katayama K, Akın G. Agerelated patterns of upper arm muscle and fat area in Turkish children and assessment of nutritional status. Int J Anthropol 2006;21:231-39.

13. Monir Z, Galal A, Erfan M, Ruby ME. Assessment of growth and nutritional status of Egyptian children and adolescents, using upper arm muscle area by height. Res J Med Med Sci 2008;3:60-6. 
14. Chowdhury SD, Ghosh T. The upper arm muscle and fat area of Santal children: an evaluation of nutritional status. Acta Paediatr 2009;98:103-6.

15. Basu D, Sun D, Banerjee I, Singh M, Kalita JG, Rao VR. Cross-sectional reference values of upper arm anthropometry of the Khasi tribal adolescents of Meghalaya, India. Asia Pac J Clin Nutr 2010;19:28388.

16. Singh J, Mondal N. Use of upper-arm anthropometry as measure of body-composition and nutritional assessment in children and adolescents (6-20 years) of Assam, Northeast India. Ethiop J Health Sci 24:243-52.

17. Senbanjo IO, Oshikoya KA, Njokanma OF. Upper arm composition and nutritional status of school children and adolescents in Abeokuta, Southwest Nigeria. World J Pediatr 2014;10:336-42.

18. Medhi GK, Hazarika NC, Mahanta J. Nutritional status of adolescents among tea garden workers. Indian J Pediatr 2007;74:343-47.

19. Mondal N, Sen J. Prevalence of undernutrition among children (5-12 years) belonging to three communities residing in a similar habitat in North Bengal, India. Ann Hum Biol 2010;37:199-217.

20. Mondal N, Sen J. Prevalence of stunting and thinness among rural adolescents of Darjeeling district, West Bengal, India. Ital J Pub Health 2010;7:54-61.

21. de Onis M, Dasgupta P, Saha S, Sengupta D, Blössner M. The National Center for Health Statistics reference and the growth of Indian adolescent boys. Am J Clin Nutr 2001;74:248-53.

22. Khongsdier R, Mukherjee N. Growth and nutritional status of Khasi boys in Northeast India relating to exogamous marriages and socioeconomic classes. Am J Phys Anthropol 2003;122:162-70.

23. Lee MM, Sergeyev O, Williams P, Korrick S, Zeilert V, Revich B, Hauser R. Physical growth and sexual maturation of boys in Chapaevsk, Russia. J Pediatr Endocrinol Metab 2003;16:169-78.

24. Kumar V, Basu D, Reddy BM. Genetic heterogeneity in northeastern India: reflection of Tribe-Caste continuum in the genetic structure. Am J Hum Biol 2004;16:334-45.

25. Touitou Y, Portaluppi F, Smolensky MH, Rensing L. Ethical principles and standards for the conduct of human and animal biological rhythm research. Chronobiol Int 2004; 21:161-70.

26. Mishra D, Singh HP. Kuppuswami's socioeconomic status scale - A revision. Indian J Pediatr 2003;70:273-74.
27. Gibson RS. 2005. Principle of nutritional assessment. Oxford: Oxford University Press.

28. UlijaszekSJ, KerrDA. Anthropometric measurement error and the assessment of nutritional status. $\mathrm{Br} \mathrm{J}$ Nutr 1999;82:165-77.

29. Cole TJ, Green PJ. Smoothing reference centile curves: the LMS method and penalized likelihood. Stat Med 1992;11:1305-19.

30. Cole TJ, Freeman JV, Preece MA. British 1990 growth reference centiles for weight, height, body mass index and head circumference fitted by maximum penalized likelihood. Stat Med 1998;17:407-29.

31. Frisancho AR. Anthropometric standards: An interactive nutritional reference of body size and body composition for children and adults. Ann Arbor: The University of Michigan press, 2008.

32. Kuczmarski RJ, Ogden CL, Guo SS, et al. 2000 CDC growth charts for the United States: Methods and development. National Center for Health Statistics. Vital Health Stat 2002;11(246):1-190

33. World Health Organization (WHO). WHO child growth standards: head circumference-for-age, arm circumference-forage, triceps skinfold-for-age and subscapular skinfold-for-age: methods and development. Geneva, World Health Organization, 2007, available:http://www.who.int/childgrowth/ standards/second_set/technical_report_2/en/.

34. Sen B, Bose K, Shaikh S, Mahalanabis D. Prediction equations for body-fat percentage in Indian infants and young children using skinfold thickness and mid-arm circumference. J Health Popul Nutr 2010;28:221-9.

35. Strickland SS. Functional consequences of adult malnutrition in developing countries: a review. $J$ Physiol Anthropol Appl Human Sci 2002;21:1-9.

36. Ulijaszek SJ. The international growth standard for children and adolescents project: environmental influences on preadolescent and adolescent growth in weight and height. Food Nutr Bull 2006;27:S279-94.

37. Akinbami FO, Hamzat $\mathrm{TH}$, Orimadegun $\mathrm{AE}$, Tongo O, Oyeyemi L, Okafor O, Akinyinka OO. Body mass composition: a predictor of admission outcomes among hospitalized Nigerian under 5 children. Asia Pac J Clin Nutr 2010;19:295-300.

38. Ribas SA, Santana da Silva LC. Anthropometric indices: predictors of dyslipidemia in children and adolescents from north of Brazil. Nutr Hosp 2012;27:1228-35. 